ORIGINAL ARTICLE

\title{
Effectiveness of Nalbuphine with Ropivacaine in Supraclavicular Brachial Plexus Block in Patients Undergoing Upper Limb Surgeries
}

\author{
KHALID ABAIDULLAH ${ }^{1}$, ABID ALI KHAN ${ }^{2}$, NOMAN TARIQ ${ }^{3}$, IMRAN SADIQ ${ }^{4}$ \\ ${ }^{1}$ Assistant Professor, Department of Anaesthesia, Fatima Memorial Hospital/College of Medicine \& Dentistry, Lahore \\ ${ }^{2}$ Orthopaedic Surgeon, King Abdullah Teaching Hospital, Mansehra \\ ${ }^{3}$ Assistant Professor, Department of Anaesthesia, Lahore Medical \& Dental College/Ghurki Trust Teaching Hospital, Lahore \\ ${ }^{4}$ Assistant Professor, Department of Surgery, Fatima Memorial Hospital/College of Medicine \& Dentistry, Lahore \\ Correspondence to: Dr. Khalid Abaidullah, E-mail: khalidabaidullah@yahoo.com, Cell: 0321-4341491
}

\begin{abstract}
Objective: To investigate the effectiveness of ropivacaine in supraclavicular brachial plexus block by nalbuphine and compare it to ropivacaine alone.

Study Design: Randomized controlled trial

Place and Duration of Study: Department of Anaesthesia, Fatima Memorial Hospital/College of Medicine \& Dentistry, Lahore from 1st June 2020 to $31^{\text {st }}$ March 2021.

Methods: Ninety six patients of both genders with ages 20 to 65 years undergoing upper limb surgical procedure electively were included. All the patients were divided equally in to two groups, each group consist of 48 patients. Group A treated with ropivacaine with nalbuphine and group B treated with ropivacaine normal saline. Effectiveness between both groups was examined.

Results: No significant difference was observed regarding age, gender, body mass index and ASA class I/II between both groups with $p$-value $>0.05$.A significant difference was found regarding onset time of sensory and motor block between both groups $(p=0.001)$. Mean sensory block duration in group A was more $425.18 \pm 17.82$ minutes as compared to group B $254.43 \pm 20.44$ minutes. Mean duration of motor block was also more in group A $418.65 \pm 20.84$ minutes as compared to group B 226.15 \pm 12.52 minutes. Duration of analgesia was high in group A as compared to group B with p-value $<0.05$.

Conclusion: In supraclavicular brachial plexus block $0.75 \%$ with $10 \mathrm{mg}$ of nalbuphine is particularly effective in sensory, motor, and analgesic periods in relation to ropivacaine alone.

Keywords: Supraclavicular, Brachial plexus block, Ropivacaine, Nalbuphine, Duration of analagesia
\end{abstract}

\section{INTRODUCTION}

A highly effective regional anaesthesia procedure for high arm surgeons is the supraclavicular brachial plexus nerve block. It is a reliable alternative to general anaesthesia for certain patients since it lacks the unwanted effects of general anaesthesia and laryngoscopy stress. The postoperative period is also free from pain, nausea, vomiting, and respiratory depression. The supraclavicular approach is chosen for brachial plexus block as here it is enclosed in a fascial sheath that extends from neck to the axilla. ${ }^{1}$

The success of brachial plexus block relies on nerve localization, needle placement, and deposition of local anaesthetic solution at right place by a single injection of local anesthetic. ${ }^{1}$ The conventional blind technique relies on surface landmarks before needle insertion and elicitation of paresthesia while ultrasound guidance detects the anatomical variants of brachial plexus and related anatomical structures, accurate needle placement, and monitoring of drug spread in the appropriate tissue planes with painless performance. Ultrasound increases the success rate and reduces the injury to adjacent structures. ${ }^{2-4}$ It also minimized the local anaesthetic volume, thereby reducing the incidences of their systemic toxicity. ${ }^{5}$

Ropivacaine, an amid LA, has decreased potential for the central nervous system toxicity and cardiotoxicity due to reduced lipophilicity which provides wider safety margin. ${ }^{6,7}$ Due to brief duration of action of LAs, various adjuvants along with LAs has been tried to extend the duration of analgesia in regional blocks. Peripheral opioid administration prolongs analgesia without producing systemic side effects. Nalbuphine is a mixed k-agonist- $\mu$ antagonist opioid which, compared with morphine, has moderate analgesic efficacy. Easier to use than other regularly used opioids, low cost and less adverse effects make it better. 8

We performed this research to assess the efficacy of ropivacane alone in the supraclavicular brachial plexus block and compare it with nalbuphine and ropivacaine

\section{MATERIALS AND METHODS}

This randomized controlled trial was conducted at Department of Anaesthesia, Fatima Memorial Hospital/College of Medicine \& Dentistry Lahore from 1st June 2020 to $31^{\text {st }}$ March 2021. A total of 96 patients of both genders with ages 20 to 70 years undergoing upper limb surgical procedures electively were enrolled in this study. Patients detailed demographics including age, sex, body mass index, and ASA class I or II were recorded after written consent from all the patients. Clinically noteworthy patients coagulopathy, site infection, local anaesthesia allergy, neuromuscular pre-existence, severe cardiovascular, or pulmonary disease, renal or hepatic disorder, refusal to technique, or no ability to visualize ultrasound guidance or block failure brachial plexus were excluded.

All the patients were divided equally in to two groups, each group consist of 48 patients. Group A received $25 \mathrm{ml}$ of ropivacaine $0.75 \%$ with $1 \mathrm{ml}(10 \mathrm{mg})$ nulbuphine and group B received $25 \mathrm{ml}$ of $0.75 \%$ ropivacaine with normal saline. All the patients received brachial plexus block 
through the supraclavicular approach using US guidance (The Sonosite Micromaxx ${ }^{\mathrm{TM}}$ Bothell, Washington, USA machine with a 6-13 $\mathrm{MHz}$ linear probe) by an experienced anesthesiologist. A $21 \mathrm{G} 50 \mathrm{~mm}$ short bevelled insulated needle was inserted under US guidance under all aseptic precaution. Effectiveness of doses in term of onset time to sensory and motor block, time duration of sensory and motor block and duration of analgesia were examined and compare the findings between both groups.

All the data was analyzed by SPSS 24.0. Mean \pm SD was done. Chi-square test was applied to compare the parameters between both groups with $p$-value $<0.05$ was taken as significant.

\section{RESULTS}

There were $30(62.5 \%)$ male and $18(37.5 \%)$ female with mean age $36.48 \pm 12.44$ years group $A$, and group B34 $(70.83 \%)$ were male and $14(29.17 \%)$ were females with mean age $37.08 \pm 11.37$ years. Mean BMl of group $A$ patients was $23.02 \pm 2.86 \mathrm{~kg} / \mathrm{m}^{2}$ and in group $B$ it was $23.45 \pm 2.68 \mathrm{~kg} / \mathrm{m}^{2}$. In group A $38(79.17 \%)$ patients had ASA class I and $10(20.83 \%)$ had ASA class II, in group II $40(83.33 \%)$ and $8(16.67 \%)$ patients had ASA class I and II. No significant difference was observed between both groups regarding age, gender, BMI and ASA class with $\mathrm{p}$ value $>0.05$ (Table 1 )

Table 1: Demographics of all the patients

\begin{tabular}{|l|l|l|}
\hline Variable & Group A & Group B \\
\hline Mean age (years) & $36.48 \pm 12.44$ & $37.08 \pm 11.37$ \\
\hline Mean BMI $\left(\mathrm{kg} / \mathrm{m}^{2}\right)$ & $23.02 \pm 2.86$ & $23.45 \pm 2.68$ \\
\hline Gender & $30(62.5)$ & $34(70.83)$ \\
\hline Male & $18(37.5)$ & $14(29.17)$ \\
\hline Female & $38(79.17)$ & $40(83.33)$ \\
\hline ASA class & $10(20.83)$ & $8(16.67)$ \\
\hline I &
\end{tabular}

P-value $>0.05$

Table 2: Comparison of onset time to sensory and motor block between both groups

\begin{tabular}{|l|l|l|l|}
\hline Variables & Group A & Group B & P-value \\
\hline $\begin{array}{l}\text { Mean onset sensory } \\
\text { block (min) }\end{array}$ & $8.12 \pm 2.14$ & $13.47 \pm 4.77$ & 0.002 \\
\hline $\begin{array}{l}\text { Mean onset motor } \\
\text { block (min) }\end{array}$ & $9.42 \pm 2.14$ & $13.88 \pm 3.56$ & 0.004 \\
\hline
\end{tabular}

Table 3: Comparison of time duration of sensory and motor block and duration of analgesia between both groups

\begin{tabular}{|l|l|l|l|}
\hline Variables & Group A & Group B & P-value \\
\hline $\begin{array}{l}\text { Mean duration } \\
\text { sensory block }\end{array}$ & $425.18 \pm 17.82$ & $254.43 \pm 20.44$ & $<0.001$ \\
\hline $\begin{array}{l}\text { Mean duration } \\
\text { motor block }\end{array}$ & $418.65 \pm 20.84$ & $226.15 \pm 12.52$ & $<0.001$ \\
\hline $\begin{array}{l}\text { Duration of } \\
\text { analgesia }\end{array}$ & $698.72 \pm 15.55$ & $436.52 \pm 22.43$ & $<0.001$ \\
\hline
\end{tabular}

Mean time onset to sensory block in group $A$ was $8.12 \pm 2.14$ minute while in group $B$ it was $13.47 \pm 4.77$ minute, a significant longer time was observed in group $B$ as compared to group A with p-value 0.002. In group A mean time onset to motor block was $9.42 \pm 2.14$ minutes and in group B it was $13.88 \pm 3.56$ minutes, a significant difference was observed between both group $[\mathrm{p}=0.004]$ (Table 2).

Mean sensory block duration in group A was more $425.18 \pm 17.82$ minutes as compared to group B $254.43 \pm 20.44$ minutes. Mean duration of motor block was longer in group A $418.65 \pm 20.84$ minutes as compared to group $B 226.15 \pm 12.52$ minutes. The analgesic duration in Group A was longer than in group B with $p$-value $<0.05$ (Table 3).

\section{DISCUSSION}

Many medications have been employed with a superclavicular approach for the greater efficacy of the brachial plexus block, with better efficacy of bupvicaine and nulbuphene. ${ }^{9,10}$ We conducted present study to examine the effectiveness of nalbuphine $10 \mathrm{mg}$ with $0.75 \%$ ropivacaine and compare with ropivacaine $0.75 \%$ alone in supraclavicular brachial plexus block under ultrasound guidance. In this regard 48 patients whom were undergoing upper limb surgical procedures electively were enrolled in this study. Majority of patients in both groups $A$ and $B$ were male $62.5 \%$ and $70.83 \%$ and females were $37.5 \%$ and $29.17 \%$. Mean age of patients in ropivacaine + nalbuphine group was $36.48 \pm 12.44$ years and in ropivacaine alone group was $37.08 \pm 11.37$. These results was comparable to many of previous studies in which male patients were predominant as compared to females $65 \%$ to $80 \%$ Vs $30 \%$ to $40 \%$ and the average age of patients was 40 years. ${ }^{11,12}$ We found no significant difference regarding body mass index and ASA class I and II. A study by Chattopadhyay et $\mathrm{a}^{13}$ regarding efficacy of nalbuphine as an adjuvant to $0.5 \%$ bupvicaine reported that mean BMI of nalbuphine with bupvicaine group patients was $21.63 \pm 3.21$ and in other group it was $20.58 \pm 2.78 \mathrm{~kg} / \mathrm{m}^{2}$.

In present study, mean time onset to sensory block in group A was $8.12 \pm 2.14$ minute while in group B it was $13.47 \pm 4.77$ minute, group $B$ observed a much longer duration than group $A$ with $p$-value 0.002 . In group $A$, mean time onset to motor block was $9.42 \pm 2.14$ minutes and in group $B$ it was $13.88 \pm 3.56$ minutes, a significant difference was observed between both group ( $p$-value 0.004). These results were similar to the study by Rehman et $\mathrm{al}^{14}$ regarding analgesic effectiveness of nalbuphine as an adjuvant to bupvicaine reported that patients received nalbuphine with bupvicaine had significantly shorter onset time to sensory and motor block as compared to bupvicaine alone with $p$-value $<0.05$. Another study by Nethra et al $^{15}$ reported there was no significant difference between both groups (nalbuphine with ropivicaine and ropivicaine alone) regarding onset time to sensory and motor block $11.58 \pm 3.56$ vs $10.84 \pm 3.24 \quad(p=0.40)$ and $13.12 \pm 4.98$ vs $11.23 \pm 3.29(p=0.09)$.

In this study, patients whom were received nalbuphine as an adjuvant to ropivacaine had significantly longer duration of sensory block $425.18 \pm 17.82$ minutes and motor block $418.65 \pm 20.84$ minutes also had longer duration of rescue analgesia $698.72 \pm 15.55$ minute as compared to patients whom were received ropivacaine alone sensory block 254.43 \pm 20.44 minute, motor block $226.15 \pm 12.52$ minutes and rescue analgesia $436.52 \pm 22.43$ minutes. These results were comparable to many of previous studies in which patients received nalbuphine as an 
adjuvant to $0.5 \%$ and $0.75 \%$ ropivacaine had significantly longer time duration to sensory, motor block and rescue analgesia when compared to bupvicaine alone. ${ }^{15-17}$

We found no significant difference regarding hemodynamic changes between both groups and none of patients had developed any adverse effect.

\section{CONCLUSION}

In supraclavicular brachial plexus block $0.75 \%$ with $10 \mathrm{mg}$ of nalbuphine is particularly effective in sensory, motor, and analgesic periods in relation to ropivacaine alone. In addition, in both groups, none of the patients had a complication.

\section{REFERENCES}

1. Nayagam HA, Singh NR, Singh HS. A prospective randomised double blind study of intrathecal fentanyl and dexmedetomidine added to low dose bupivacaine for spinal anaesthesia for lower abdominal surgeries. Indian J Anaesth 2014;58: 430-35.

2. Kim MH, Lee YM. Intrathecal midazolam increases the analgesic effects of spinal blockade with bupivacaine in patients undergoing haemorrhoidectomy. $\mathrm{Br} J$ Anaesth 2001;86:77-79.

3. Benyamin R, Trescot AM, Datta S, Buenaventura R, Adlaka $\mathrm{R}$, Sehgal $\mathrm{N}$, et al. Opioid complications and side effects. Pain Physician 2008; 11 (2 Suppl): S105-20.

4. Talke $P$, Richardson CA, Scheinin M, Fisher DM. Postoperative pharmacokin etics and sympatholytic effects of dexmedetomidine. Anaesth Analg 1997; 85(5): 1136-42.

5. Zhang Y, Shan Z, Kuang L, Xu Y, Xiu H, Wen J, et al. The effect of different doses of intrathecal dexmedetomidine on spinal anaesthesia: a meta analysis. Int J Clin Exp Med 2016;9(10):18860-86.

6. Mohamed AA, Fares KM, Mohamed SA. Efficacy of intrathecally administered dexmedetomidine versus dexmedetomidine with fentanyl in patients undergoing major abdominal cancer surgery. Pain Physician 2012;15:339-48.

7. Sudheesh K, Raghavendra RS, Kavya M, Aarthi J, Rani DD, Nethra SS. Comparative study of two doses of intrathecal dexmedetomidine as adjuvant with low dose hyperbaric bupivacaine in ambulatory perianal surgeries: a prospective randomised controlled study. Indian J Anaesth 2015; 59:64852.

8. Grewal A. Dexmedetomidine: new avenues. J Anaesthesiol Clin Pharmacol 2011;27:297-302.

9. Gupta R, Verma R, Bogra J, Kohli M, Raman R, Kushwaha $\mathrm{JK}$, et al. Acomparative study of intrathecal dexmedetomidine and fentanyl as adjuvants to bupivacaine. J Anaesthesiol Clin Pharmacol 2011; 27:339-43.

10. Kim JE, Kim NY, Lee HS, Kil HK. Effects of intrathecal dexmedetomidine on low-dose bupivacaine spinal anesthesia in elderly patients undergoing transurethral prostatectomy. Biol Pharm Bull 2013; 36:959-65

11. Rai A, Bhutia MP. Dexemedetomidine as an additive to spinal anaesthesia in orthopaedic patients undergoing lower limb surgeries: a randomized clinical trial comparing two different doses of dexmedetomidine. J Clin Diagn Res 2017; 11(4):UC09-12.

12. Dinesh CN, Sai Tej NA, Yatish B, Pujari VS, Mohan Kumar RM, Mohan CV. Effects of intravenous dexmedetomidine on hyperbaric bupivacaine spinal anesthesia: a randomized study. Saudi J Anaesth 2014; 8(2):202-208.

13. Chattopadhyay I, Banerjee SS, Jha AK, Basu S. Effects of intrathecal dexmedetomidine as an additive to low-dose bupivacaine in patients undergoing transurethral resection of prostate. Indian J Anaesth 2017;61:1002-8.

14. Rehman AU, Siddiq S, Qadeer K, Nawaz A, Hussain K, Ashfaq N, Aziz L. Analgesic effects of dexmedetomidine with hyperbaric bupivacaine in spinal anesthesia for patients undergoing Illiazorov surgery. Anaesth Pain Intensive Care 2019; 23(1):59-62.

15. Nethra SS, Sathesha M, Dixit A, Dongare PA, Harsoor SS, Devikarani D. Intrathecal dexmedetomidine as adjuvant for spinal anaesthesia for perianal ambulatory surgeries: a randomised double-blind controlled study. Indian J Anaesth 2015; 59(3):177-81.

16. Teymourian $\mathrm{H}$, Khorasanizadeh $\mathrm{S}$, Ansar $\mathrm{P}$, Nazari $\mathrm{L}$, Ebrahimy Dehkordy M. Comparison of the effect of bupivacaine in combination with dexmedetomidine with bupivacaine plus placebo on neonatal apgar score, bispectral index, and sedation level of parturient women. Anesth Pain Med 2018; 8(5):e81947.

17. Liu L, Qian J, Shen B, Xiao F, Shen H. Intrathecal dexmedetomidine can decrease the $95 \%$ effective dose of bupivacaine in spinal anesthesia for cesarean section: a prospective, double-blinded, randomized study. Medicine 2019;98(9):e14666. 